\title{
HEMI ABDOMEN RESURFACING WITH A LARGE KEYSTONE FLAP FOR MULTIPLE MARJOLIN ULCERS WITH FIELD CHANGE IN A BURNS SCAR AFTER 70 YEARS
}

Pinto-Lopes R., Murphy S., Loh C., Reid A., Gkorgkolis V., Barnes, D., El-Muttardi, N.

St. Andrews Centre for Plastic Surgery and Burns

Mid and South Essex University Hospitals Group, Chelmsford, United Kingdom

Mid and

South Essex

University Hospitals Group

\section{INTRODUCTION}

\begin{abstract}
Marjolin Ulcers (MU) refer to areas of malignant transformation in burn scars $^{1,2}$. These are usually squamous cell carcinomas $^{9}$ but may be of rarer types such as basal cell carcinomas (BCCs), melanomas or sarcomas. They may appear after a variable period of time and can be extensive and infiltrative in nature.
\end{abstract}

We present a patient who had multiple burns scars over the anterior surface of her abdomen and left groin which were biopsy proven BCCs.

The degree of field change and close location of each burns scar to the other made individual excision and reconstruction challenging.

We describe our management of this case and reconstruction of half the abdominal wall with a large keystone flap

\section{METHODS}

Complete oncological excision of the affected burns scars and MU was performed under general anaesthesia to the fascial wall.

A large keystone flap was designed after marking it out in Huger Zone 3.

Perforators identifiable from the intercostal, subcostal region were preserved during the dissection and mobilised, ensuring viability of the flap.

A separate $\mathrm{MU}$ in the left groin was resurfaced with a pedicled vastus lateralis flap with split thickness skin graft.

\section{DISCUSSION}

Large keystone flaps in the trunk are useful for managing multiple burn scars with MU change. After oncological excision, resurfacing the hemiabdominal wall with a flap provides the best outcome if further radiotherapy is required.

\section{RESULTS}

The patient had complete clearance of the tumour infiltrated burns scars and the hemi abdomen was completely reconstructed with a keystone flap without issue.

Fig 1. Hemi abdomen reconstruction with keystone flap

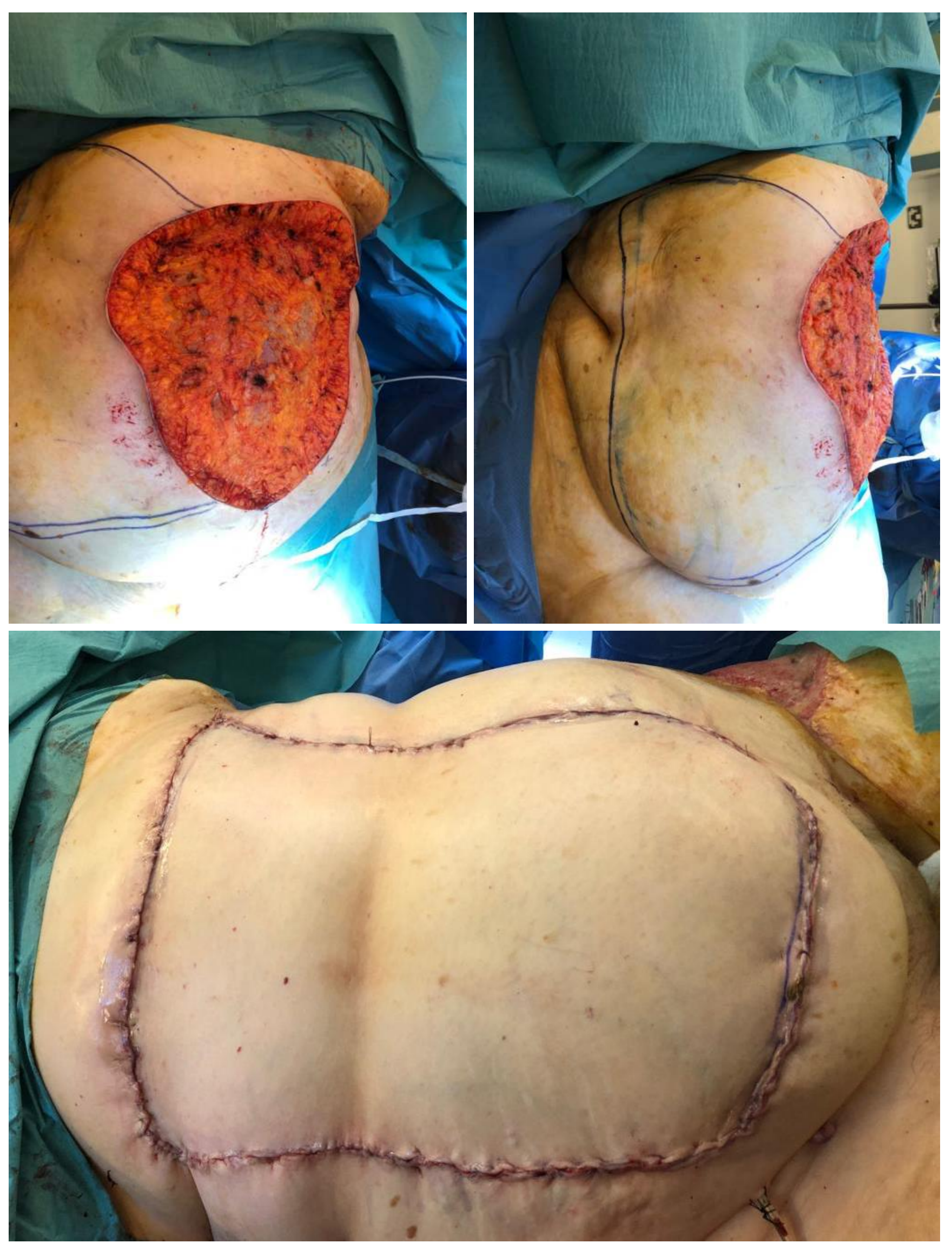

REFERENCES 